\title{
MOTHERS' FEAR, THEIR CHILDREN'S WELL-BEING IN HOSPITAL, AND THE STUDY OF ILLNESS BEHAVIOUR
}

\author{
BY \\ DAVID ROBINSON, Ph.D. \\ Research Fellow in Sociology, School of Social Studies, University College, Swansea
}

Attempts to identify problems connected with the hospitalization of young children have usually focused on the children themselves and paid little attention to the children's parents. Nevertheless there is ample support in the literature for the commonsense notion that parents, and especially mothers, may suffer extreme distress over their children's illness, hospitalization, and surgery (Skipper, 1966; Mechanic, 1964), and that their relationship with the child at this time plays a significant part in the child's social and psychological adjustment to the hospital situation (Jensen and Comly, 1948). This paper makes a number of tentative propositions about the relationship between fear and certain attitudes and actions in the fear situation, and discusses some of the implications of this relationship, first for the well-being of young children in hospital and secondly for the study of illness behaviours.

\section{MeTHODS}

This paper arose incidentally out of material from the wide-ranging structured interviews of a social survey. It has nothing to say, therefore, about the cause of the particular fear being discussed or methods for its alleviation. The interviews were carried out with 337 mothers whose under 5-year-old children had been admitted to one of seven South Wales hospitals during 1964. Reference is also made to material from interviews with $\mathbf{4 2}$ mothers who had lived in hospital with their sick children at the Amersham General Hospital mothers-in unit in 1964.

Fear of being hospitalized was measured by the paired-sentence technique developed for epidemiological purposes by Ingham (1965) from a procedure devised by Shapiro (1961). The four-sentence battery, arranged in order from Statement 1 , admitting to least fear of being hospitalized, to Statement 4, ad- mitting the greatest amount of fear of being hospitalized, was:

(1) The thought of being a hospital patient never worries me at all.

(2) Sometimes I am slightly worried by the thought of being a hospital patient.

(3) The thought of being a hospital patient often worries me.

(4) The thought of being a hospital patient alwaye terrifies me.

Responses to the series of paired sentences allowe us to place mothers in one of three categories. The number of mothers in each category is displayed in Table I. When reference is made to those mothers who were most afraid of being hospitalized it should be borne in mind that they represent approximately 20 per cent. of the South Wales hospitals sample.

TABLE I

MOTHERS' FEAR OF BEING HOSPITALIZED

\begin{tabular}{l|c|c}
\hline \multicolumn{1}{c|}{ Degree of Fear } & No. & Per cent. \\
\hline Mothers least afraid of being hospitalized & 197 & $60 \cdot 8$ \\
A middle group & 67 & $20 \cdot 7$ \\
Mothers most afraid of being hospitalized & 60 & $18 \cdot 5$ \\
\hline Total & $324^{*}$ & \\
\hline
\end{tabular}

* Five of the mothers were either unwilling or unable to carry out the paired-sentence procedure, while another eight mothers had "inconsistent" response patterns. "A consistent response pattern is one in which no two responses indicate mutually inconsistent positions on the scale." (Ingham, 1965, p. 136.)

\section{Perception}

\section{RESULTS}

There is some experimental evidence that the $\widetilde{O}$ arousal of fear results in a tendency to perceive other people as fearful and anxious. (Feshbach and Singer, 1957). This is supported by the present study. When mothers were asked to say what they were most concerned about when they knew that their child was to 
be admitted to hospital, it was possible to group their answers into three main categories: mothers who said that they had no concern; mothers who were most concerned about the child's illness, its treatment, or its outcome; and mothers who were most concerned about the possiblity of their child grieving or being frightened in hospital. If the "fearful perceives fear" hypothesis is to receive support, then the group which is most afraid of being hospitalized should contain the largest proportion of mothers who are concerned about the child's fear as opposed to its illness. Table II shows that there was significant relationship $(P<0.05)$ between a high level of fear of being hospitalized herself and a mother's concern about her child's grieving as opposed to its illness.

TABLE II

FEAR AND MOTHERS' CONCERN AT CHILD'S ADMISSION

\begin{tabular}{l|l|c|c|c|c|c|c}
\hline \multirow{2}{*}{ Concern } & \multicolumn{2}{|c|}{ Least Fear } & \multicolumn{2}{c|}{ Medium Fear } & \multicolumn{2}{c|}{ Most Fear } & \multirow{2}{*}{ Total } \\
\cline { 2 - 6 } & No. & $\begin{array}{c}\text { Per- } \\
\text { cent. }\end{array}$ & No. & $\begin{array}{c}\text { Per- } \\
\text { cent. }\end{array}$ & No. & $\begin{array}{c}\text { Per- } \\
\text { cent. }\end{array}$ & \\
\hline About illness & 84 & $54 \cdot 9$ & 35 & $63 \cdot 6$ & 17 & $37 \cdot 8$ & 136 \\
About grieving & 69 & $45 \cdot 1$ & 20 & $36 \cdot 4$ & 28 & $62 \cdot 2$ & 117 \\
\hline Total & 153 & & 55 & & 45 & & 253 \\
\hline No answer or "inconsistent" on fear & & & 13 \\
\hline Total
\end{tabular}

$\chi^{2}=6.85 ; \quad d$ of $f=2 ; \quad P<0.05$.

* In addition to the three categories specified for the purpose of this section there were 38 other responses to the question about concern at admission. These mothers were concerned about food, visiting, the child losing weight, both illness and separation, and about "leaving the child in hospital". 33 other mothers said that they had no concern at all.

\section{INTENTION AND ACTION}

If mothers who are afraid of being hospitalized themselves tend to be more likely to think that their children are also afraid we should expect this to affect the amount of general preparation they give their children for being hospitalized. For the purposes of this study general preparation was defined in terms of three hospital-orientated activities: watching hospital programmes on television, reading books about hospitals, and playing hospital games. A large number of the children were considered by their mothers to be too young for this kind of activity. Of the 95 effective cases which remained, 58 received some preparation as defined above. This, however, was dependent to some extent upon whether the admission was an emergencyone ornot. Non-emergency cases had more preparation.

Although the relationship between fear and amount of general preparation did not reach the conventional level of significance, an increase in the mother's fear tended to be associated with a decrease of hospital-orientated activities. This overall tendency was modified, however, when the already-mentioned factor of emergency admission was introduced. Table III shows that, for the mothers of emergency admissions, the relationship between an increase in fear and a decrease in preparation is maintained; for the mothers of non-emergency admissions this is reversed.

TABLE III

FEAR AND AMOUNT OF GENERAL PREPARATION (EMERGENCY AND NON-EMERGENCY ADMISSIONS)

\begin{tabular}{|c|c|c|c|c|c|}
\hline Admission & Preparation & $\begin{array}{l}\text { Least } \\
\text { Fear }\end{array}$ & $\underset{\text { Fear }}{\text { Medium }}$ & $\begin{array}{l}\text { Most } \\
\text { Fear }\end{array}$ & Total \\
\hline \multirow[t]{2}{*}{ Emergency } & $\begin{array}{l}\text { None } \\
\text { Some }\end{array}$ & $\begin{array}{l}11 \\
16\end{array}$ & $\begin{array}{l}8 \\
9\end{array}$ & $\begin{array}{l}7 \\
3\end{array}$ & $\begin{array}{l}26 \\
28\end{array}$ \\
\hline & Total & 27 & 17 & 10 & 54 \\
\hline \multirow[t]{2}{*}{$\begin{array}{l}\text { Non- } \\
\text { Emergency }\end{array}$} & $\begin{array}{l}\text { None } \\
\text { Some }\end{array}$ & $\begin{array}{r}6 \\
18\end{array}$ & $\begin{array}{l}1 \\
5\end{array}$ & $\begin{array}{l}1 \\
6\end{array}$ & $\begin{array}{r}8 \\
29\end{array}$ \\
\hline & Total & 24 & 6 & 7 & 37 \\
\hline
\end{tabular}

Although the numbers in Table III are small, they do suggest that, while in the normal run of things mothers who are afraid of being hospitalized seem less likely to encourage hospital-orientated activities for their children at home, this tendency is reversed when the mothers are confronted with definite knowledge that their children are going to be hospitalized.

For almost half the mothers $(44 \cdot 2$ per cent.) an unrestricted visiting system was operating for the wards in which their children were patients. Of the other mothers just over two-thirds said that they would have taken advantage of such a system if it had been available. Just as an increase in the mother's fear of being hospitalized seems to make her more aware of the needs to prepare the child she knows is to be hospitalized, so in the same way, as Table IV shows, the more frightened she is the more likely she is to desire to take advantage of an unrestricted visiting system.

TABLE IV

FEAR AND MOTHERS' DESIRE FOR UNRESTRICTED VISITING

\begin{tabular}{l|r|r|r|r|r|r|r}
\hline \multirow{2}{*}{$\begin{array}{c}\text { Unrestricted } \\
\text { Visiting }\end{array}$} & \multicolumn{2}{|c|}{ Least Fear } & \multicolumn{2}{|c|}{ Medium Fear } & \multicolumn{2}{|c|}{ Most Fear } & \multirow{2}{*}{ Total } \\
\cline { 2 - 7 } & No. & $\begin{array}{r}\text { Per- } \\
\text { cent. }\end{array}$ & No. & $\begin{array}{c}\text { Per- } \\
\text { cent. }\end{array}$ & No. & $\begin{array}{c}\text { Per- } \\
\text { cent. }\end{array}$ & \\
\hline $\begin{array}{l}\text { Would have liked } \\
\text { Would not } \\
\text { have liked }\end{array}$ & 71 & $62 \cdot 8$ & 25 & $73 \cdot 5$ & 17 & $77 \cdot 3$ & 113 \\
\hline Total & 42 & $37 \cdot 2$ & 9 & $26 \cdot 5$ & 5 & $22 \cdot 7$ & 56 \\
\hline
\end{tabular}

This having been said, however, mothers appear to be reluctant to translate their intentions into action. This showed itself in two ways. Dealing again with those mothers who did not have unrestricted visiting: 
just under a quarter of them knew that it was the official policy of the Hospital Management Committee that such a system should be in operation. Table $\mathrm{V}$ shows that the proportion of mothers who knew that unrestricted visiting was official policy but reported restricted visiting as being in operation in their children's wards was greatest among those who were most afraid of being hospitalized. Whether these mothers lied about ward regulations in order to justify spending only a short time in hospital themselves, or whether it was the case that they were more reluctant than other mothers to make any demands for the implementation of what they knew to be the official Hospital Management Committee visiting policy, is impossible to say.

TABLE V

FEAR AND KNOWLEDGE OF OFFICIAL HOSPITAL MANAGEMENT COMMITTEE POLICY

\begin{tabular}{|c|c|c|c|c|c|c|c|}
\hline \multirow{2}{*}{$\begin{array}{c}\text { Hospital } \\
\text { Comagement } \\
\text { Policy }\end{array}$} & \multicolumn{2}{|c|}{ Least Fear } & \multicolumn{2}{|c|}{ Medium Fear } & \multicolumn{2}{|c|}{ Most Fear } & \multirow{2}{*}{ Total } \\
\hline & No. & $\begin{array}{l}\text { Per- } \\
\text { cent. }\end{array}$ & No. & $\begin{array}{l}\text { Per- } \\
\text { cent. }\end{array}$ & No. & $\begin{array}{l}\text { Per- } \\
\text { cent. }\end{array}$ & \\
\hline $\begin{array}{l}\text { Known } \\
\text { Not known }\end{array}$ & $\begin{array}{l}23 \\
95\end{array}$ & $\begin{array}{l}19 \cdot 5 \\
80 \cdot 5\end{array}$ & $\begin{array}{r}6 \\
29\end{array}$ & $\begin{array}{l}17 \cdot 1 \\
82 \cdot 9\end{array}$ & $\begin{array}{l}10 \\
16\end{array}$ & $\begin{array}{l}38 \cdot 5 \\
61 \cdot 5\end{array}$ & $\begin{array}{r}39 \\
140\end{array}$ \\
\hline Total & 118 & & 35 & & 26 & & 179 \\
\hline
\end{tabular}

The other sign that there is a break between intention and action also concerns the mother's actual visiting. When their children were in hospital approximately half of the mothers visited all the time that they were allowed to visit, while the rest visited only some of the time. Table VI shows that an increase in the mother's personal fear of being hospitalized is associated with a decrease in the proportion who visited all the time.

TABLE VI

FEAR AND AMOUNT OF MOTHERS' VISITING

\begin{tabular}{|c|c|c|c|c|c|c|c|}
\hline \multirow{2}{*}{ Visiting } & \multicolumn{2}{|c|}{ Least Fear } & \multicolumn{2}{|c|}{ Medium Fear } & \multicolumn{2}{|c|}{ Most Fear } & \multirow{2}{*}{ Total } \\
\hline & No. & $\begin{array}{l}\text { Per- } \\
\text { cent. }\end{array}$ & No. & $\begin{array}{l}\text { Per- } \\
\text { cent. }\end{array}$ & No. & $\begin{array}{l}\text { Per- } \\
\text { cent. }\end{array}$ & \\
\hline $\begin{array}{l}\text { All } \\
\text { Some }\end{array}$ & $\begin{array}{r}105 \\
85\end{array}$ & $\begin{array}{l}55 \cdot 3 \\
44 \cdot 7\end{array}$ & $\begin{array}{l}34 \\
33\end{array}$ & $\begin{array}{l}50 \cdot 7 \\
49 \cdot 7\end{array}$ & $\begin{array}{l}23 \\
36\end{array}$ & $\begin{array}{l}39.0 \\
61.0\end{array}$ & $\begin{array}{l}162 \\
154\end{array}$ \\
\hline Total & 190 & & 67 & & 59 & & $316^{*}$ \\
\hline
\end{tabular}

* In addition to the two groups "all" and "some", eight mothers did not visit at all.

This suggests that an increase in personal fear and heightened perception of her child's fear of hospital, while on the one hand making the mother more ready to prepare her child outside the hospital situation and more aware of the need to take advantage of the opportunity to be with her child in the hospital situation, prevents her on the other hand from acting out these intentions in the actual fear (hospital) situation. This "avoidance" in the fear situation is dealt with again later on.

When asked whether they would like to live in hospital with their sick children if such a facility was available, just under 50 per cent. of the mothers said that they definitely would. However the tendency shown with regard to unrestricted visiting, for an increase in fear to be associated with an increase in expressed readiness to be with their children all the time, is not apparent here. In fact, if anything, it is slightly reversed. Possibly the "real" effect of personal fear, seen when intentions concerning unrestricted visiting were not carried out, is operating here. What the difference between intentions and action would be on this living-in question is impossible to assess. However, the answers of the mothers who did live in with their children in Amersham General Hospital seem to suggest the same reluctance to act in order to minimize the fear they perceive in their children. The Amersham sample, presented with the same paired sentences designed to measure personal fear of being hospitalized, had, as Table VII shows, a larger proportion of both "least" and "medium" fearers tha the "intending" South Wales mothers.

\begin{tabular}{|c|c|c|c|c|c|c|}
\hline \multirow{3}{*}{ Fear } & \multicolumn{4}{|c|}{ South Wales Sample } & \multirow{2}{*}{\multicolumn{2}{|c|}{$\begin{array}{c}\text { Amersham Sample } \\
\text { Did live in }\end{array}$}} \\
\hline & \multicolumn{2}{|c|}{ Would not live in } & \multicolumn{2}{|c|}{ Would live in } & & \\
\hline & No. & Per cent. & No. & Per cent. & No. & Per cent. \\
\hline $\begin{array}{l}\text { Least } \\
\text { Medium } \\
\text { Most }\end{array}$ & $\begin{array}{l}93 \\
31 \\
33\end{array}$ & $\begin{array}{l}59 \cdot 2 \\
19 \cdot 8 \\
21 \cdot 0\end{array}$ & $\begin{array}{l}95 \\
31 \\
25\end{array}$ & $\begin{array}{l}62 \cdot 9 \\
20 \cdot 5 \\
16 \cdot 6\end{array}$ & $\begin{array}{r}28 \\
11 \\
2\end{array}$ & $\begin{array}{r}68 \cdot 3 \\
26 \cdot 8 \\
4 \cdot 9\end{array}$ \\
\hline Total & 157 & & 151 & & 41 & \\
\hline
\end{tabular}

\section{Avoidance}

"Fear is one of the most potent of the emotions and usually is linked with attempts to avoid or withdraw from a situation which is painful or unpleasant." (Young, 1947).

Withdrawal by the mothers from, and avoidance of, certain aspects of the hospital situation seem to be associated with a high degree of expressed fear of being hospitalized. There appears to be a reluctance on the part of the most frightened mothers to come into contact with the hospital staff; this shows itself first in the question on whether or not the mothers spoke to the doctor in charge of their children's case. Table VIII (opposite) shows that as the amount of personal fear of hospital increases, there is a gradual decrease in the proportion of mothers who speak to the doctor in charge. 
TABLE VIII

FEAR AND WHETHER MOTHER SPOKE TO THE DOCTOR IN CHARGE OF HER CHILD'S CASE

\begin{tabular}{|c|c|c|c|c|c|c|c|}
\hline \multirow{2}{*}{$\begin{array}{l}\text { Mother's } \\
\text { Contact with } \\
\text { Doctor }\end{array}$} & \multicolumn{2}{|c|}{ Least Fear } & \multicolumn{2}{|c|}{ Medium Fear } & \multicolumn{2}{|c|}{ Most Fear } & \multirow{2}{*}{ Total } \\
\hline & No. & $\begin{array}{l}\text { Per- } \\
\text { cent. }\end{array}$ & No. & $\begin{array}{l}\text { Per- } \\
\text { cent. }\end{array}$ & No. & $\begin{array}{l}\text { Per- } \\
\text { cent. }\end{array}$ & \\
\hline $\begin{array}{l}\text { Spoke to Doctor } \\
\text { in charge } \\
\text { Did not speak } \\
\text { to Doctor }\end{array}$ & $\begin{array}{r}104 \\
93\end{array}$ & $\begin{array}{l}52 \cdot 8 \\
47 \cdot 2\end{array}$ & $\begin{array}{l}34 \\
33\end{array}$ & $\begin{array}{l}50 \cdot 7 \\
49 \cdot 3\end{array}$ & $\begin{array}{l}23 \\
37\end{array}$ & $\begin{array}{l}38 \cdot 3 \\
61 \cdot 7\end{array}$ & $\begin{array}{l}161 \\
163\end{array}$ \\
\hline Total & 197 & & 67 & & 60 & & 324 \\
\hline
\end{tabular}

This avoidance of contact with the hospital staff showed itself quite markedly again among the group of mothers who said that they had a complaint about some aspects of their child's hospitalization. Of the 104 mothers who had a complaint, just under half did not complain to anyone about it. Whether they complained or not is shown, in Table IX, to be related to the amount of their fear of being hospitalized themselves. As fear increases the proportion of those who complain decreases.

TABLE IX

FEAR AND WHETHER MOTHERS WHO HAD A COMPLAINT COMPLAINED

\begin{tabular}{l|c|c|c|c|c|c|c}
\hline \multirow{2}{*}{ Complaint } & \multicolumn{2}{|c|}{ Least Fear } & \multicolumn{2}{c|}{ Medium Fear } & \multicolumn{2}{c|}{ Most Fear } & \multirow{2}{*}{ Total } \\
\cline { 2 - 7 } & No. & $\begin{array}{c}\text { Per- } \\
\text { cent. }\end{array}$ & No. & $\begin{array}{c}\text { Per- } \\
\text { cent. }\end{array}$ & $\begin{array}{c}\text { No. } \\
\text { Per- }\end{array}$ & \\
\hline cent. & \\
\hline Did not complain & 20 & 63.6 & 12 & $50 \cdot 0$ & 8 & $36 \cdot 4$ & 55 \\
\hline Total & 55 & & 24 & & 22 & & 101 \\
\hline
\end{tabular}

Just as the mother's fear is linked with an avoidance of contact with the hospital staff, so in the same way there appears to be a connexion between fear and avoidance of what might be called the "facts of the illness situation". (This, of course, is to some extent implicit in not speaking to the doctor in charge.) Mothers were asked whether they were reassured about their child's condition at the time of admission. Table $X$ shows that, as the level of fear rises, so does the proportion of mothers who said

\section{TABLE X}

FEAR AND WHETHER MOTHERS WERE REASSURED ABOUT THEIR CHILD'S CONDITION AT ADMISSION

\begin{tabular}{l|r|c|c|c|c|c|c}
\hline \multirow{2}{*}{ Reassurance } & \multicolumn{2}{|c|}{ Least Fear } & \multicolumn{2}{|c|}{ Medium Fear } & \multicolumn{2}{c|}{ Most Fear } & \multirow{2}{*}{ Total } \\
\cline { 2 - 7 } & No. & $\begin{array}{c}\text { Per- } \\
\text { cent. }\end{array}$ & No. & $\begin{array}{c}\text { Per- } \\
\text { cent. }\end{array}$ & No. & $\begin{array}{c}\text { Per- } \\
\text { cent. }\end{array}$ & \\
\hline Reassured & 103 & $56 \cdot 3$ & 36 & $59 \cdot 0$ & 40 & $71 \cdot 4$ & 179 \\
Not reassured & 80 & $43 \cdot 7$ & 25 & $41 \cdot 0$ & 16 & $28 \cdot 6$ & 121 \\
\hline Total & 183 & & 61 & & 56 & & $300^{*}$ \\
\hline
\end{tabular}

* In 24 cases the mother did not accompany her child to hospital at its admisssion. that they were reassured about their child's condition when they accompanied it to hospital.

There was also a very slight tendency for those mothers who fear most to be least likely to want to know everything about their own condition when they are ill.

\section{ASSESSMENT}

Mothers were asked to comment on four specific points in relation to their children's hospitalization; the visiting arrangements, the nurses, in-hospital information, and their child's treatment. The relationship between fear and criticism showed a consistent pattern over all four topics, the mothers in the "medium" fear group being the most critical in each case. It is possible to offer an explanation for the lower proportion of critical mothers among the group who are most afraid of being hospitalized in terms of what had already been suggested. On the one hand the tendency to avoid both the facts and the personnel of the fear situation would not be inconsistent with also avoiding making any assessment of that situation. On the other hand, because the "fearers" perceive fear in their children and perhaps feel that they ought to be more involved than their fear allows them to be, they may tend to express satisfaction with the fear situation in order to justify their lack of contact with it and their willingness to allow their child to be in hospital alone. The low proportion of criticism among those who are least afraid of being hospitalized can perhaps be explained in terms of a lower level of concern about, as opposed to involvement in, the fear situation. This, however, is mere conjecture.

\section{Tentative Propositions}

From the information so far assembled it is possible to construct a series of tentative propositions concerning the relationship between fear and certain attitudes and behaviour in relation to the fear situation.

Persons having a high degree of personal fear tend to be more likely to perceive fear in others; to feel the need and express the desire to act in order to minimize this perceived fear; to act outside the fear situation; to avoid acting inside the fear situation; to avoid the fear situation itself; and to be less critical of aspects of the fear situation, than other people.

\section{Discussion}

Implications: for the well-being of young children in hospital

"In any culture, illness brings a degree of fear, anxiety, and distress to the stricken individual. Moreover, when the illness is serious enough to 
warrant confinement to an institution such as a hospital, the process of hospitalization itself may produce distress independent of the stress precipitated by the illness." (Skipper, 1966.)

When mothers are afraid of being hospitalized, this would seem to have implications at two levels for the well-being of their children in hospital: as a direct result of the fear itself, and as a result of the mother's behaviour in response to that fear.

It was pointed out in the introduction to this paper that parents' emotional tension is a major problem to be recognized and managed whenever a child is admitted to hospital. This is not true simply for the parents' sake but, just as importantly, for the sake of the child, since children are, of course, extremely sensitive to the feelings and emotions of other people, especially those with whom they have a very close relationship (Benedek, 1949; Coleman, 1960; Bowlby, 1963). The communication of feeling, from, for example, the mother to her child, takes place on a non-verbal as well as verbal level, can occur even with very young children, and may not be controllable by the mother. Escalona (1953), in her work with very young children, has graphically termed this type of non-verbal communication "contagion".

"An excited, worried mother,"she writes, "may try to convey reassurance, but the baby, if he is susceptible to contagion, will respond to her actual feeling state."

Thus the communication of a mother's own fear of hospital can be a significant source of distress for her child, just at a time when she could play an important part in the child's social and psychological adjustment to the hospital situation.

Similarly, the mother's behaviour in response to her fear of being hospitalized has certain implications for the well-being of her child. The tendency has been shown for the most fearful mothers to avoid the fear situation, to be less likely than other mothers to take full advantage of an unrestricted visiting system, to be less willing to live in hospital with their sick children, and to be less likely to prepare those children for their admission to hospital. This means that they are less likely to be able to preserve the vital continuity between the child's hospital and home life which does so much to mitigate the ill effects of hospitalization.

In addition, the reluctance of these mothers to come into contact both with the members of the hospital staff and with the facts of the illness situation means that they are less likely to be adequately informed about their child's hospitalization; mothers who are given a great deal of information about their child's illness, treatment, progress, and other aspects of its hospitalization suffer significantly less distress about the whole episode (Skipper, 1960). It has been noted above how a mother's distress can be transmitted to her child.

\section{Implications: for the study of illness behaviour}

"Whether we concern ourselves with the necessary conditions for building adequate etiological theories or those for bringing treatment to persons most in need of such help, it is necessary that we understand the variety of norms, values, क fears, and expected rewards and punishments on $\overrightarrow{0}$ how a symptomatic person behaves." (Mechanic, 1962.)

The concept of illness behaviour proposed by $\frac{\Omega}{\infty}$ Mechanic and Volkart (1961) refers to "the ways in $\stackrel{\rho}{子}$ which given symptoms may be differentially per- N ceived, evaluated, and acted (or not acted) upon by different kinds of people." This applies not only to the N person with symptoms but also to all other people $\infty$ involved in the illness situation. The differential be- $\frac{\text { ㅇ }}{3}$ haviour of "other people involved" is particularly important, of course, in the case of children's symptoms, since most of the contact between the child patients and professional medical services, and almost all other illness behaviour, is initiated by theix parents. This paper has reported on the differentia action of mothers in one illness situation. The differs ential action was in response to the amount of feat the mothers had of being patients in that particular situation themselves.

The sociologist or social psychologist must understand and take account of such fears if he is to construct adequate theories of illness behaviour, while the administrator cannot make accurate predictions about the use of medical facilities if such factors influencing use are not considered.

\section{SUMMARY}

379 mothers were interviewed about their attitudes and behaviour in relation to the hospitalization of their young children. One of the dimensions studied was the mothers' fear of being hospitalized themselves. This was measured by Ingham's development of Shapiro's paired-sentence technique. This paper makes a number of tentative propositions about the relationship between mothers' fear of being hospitalized and certain attitudes and actions in relation to the hospitalization of their young children. It also discusses some of the implications of this relationship for the well-being of children in hospital and for the study of illness behaviour. We have tried to show that more attention could profitably be focused on parents when the well-being of their children in hospital is being considered, and to emphasize that an understanding of the influence of fears, such as 
the one discussed here, is necessary before any adequate theories of illness behaviour can be constructed.

This paper reports some of the findings of a project concerned with social and psychiatric aspects of the welfare of children in hospital. The work was financed by the Ministry of Health $(C / 141 / 2)$ and carried out by members of the School of Social Studies, University College, Swansea (Robinson, 1967; Pill 1967, and R. Dearden (M.D. Thesis (Birmingham) in preparation) ).

\section{REFERENCES}

Benedek, T. (1949). Amer. J. Orthopsychiat., 19, 642 (The psychosomatic implications of the primary unit: Mother-Child).

Bowlby, J. (1965). "Child Care and the Growth of Love", ed. and abridged by M. Fry. Penguin Books, Harmondsworth.

Coleman, J. (1960). "Personality Dynamics and Effective Behaviour." Scott, Foresman, Chicago.

Escalona, S. (1953). "Emotional Development in the First Year of Life", in "Problems of Infancy and Childhood", Trans. VI Conference Josiah Macy, Jr., Foundation, 1952, ed. M. J. E. Senn, pp. 11-92.
Feshback, S., and Singer, R.D. (1957). J. abnorm. soc. Psychol., 55, 283 (The effects of fear arousal and suppression of fear upon social perception).

Ingham, J. G. (1965). Brit. J. soc. clin. Psychol., 4, 131 (A method for observing symptoms and attitudes).

Jensen, R. A., and Comly, H. L. (1948). Nervous Child, 7, 200 (Child-parent problems and the hospital).

Mechanic, D. (1962). J. chron. Dis., 15, 189 (The concept of illness behaviour).

(1964). Pediatrics, 33, 444 (The influence of mothers on their children's health attitudes and behaviour).

- and Volkart, E. H. (1961). Amer. sociol. Rev., 26, 51 (Stress, illness behaviour, and the sick role).

Pill, R. M. (1967). "A Social Study of the Hospitalisation of Young Children." Unpublished M.Sc. (Econ.) thesis (Wales).

Robinson, D. A. (1967). "Some Aspects of the Attitudes and Behaviour of Parents in relation to the Hospitalisation of Young Children." Unpublished Ph.D. thesis (Wales).

Shapiro, M. B. (1961). Brit. J. med. Psychol., 34, 151 (A method of measuring psychological changes specific to the individual psychiatric patient).

Skipper, J. L.. Jr. (1966). J. Marriage and the Family. p. 145. (Mothers' distress over their children's hospitalisation for tonsillectomy.)

Young, K. (1947). "Personality and Problems of Adjustment." Kegan Paul, Trench and Trubner, London. 